\title{
Water Stable Isotopes in an Alpine Setting of the Northeastern Tibetan Plateau
}

\author{
Xue Qiu ${ }^{1}\left(\right.$, Mingjun Zhang ${ }^{1, *}$, Shengjie Wang ${ }^{1,3}{ }^{\oplus}$, Athanassios A. Argiriou ${ }^{2}\left(\right.$, Rong Chen ${ }^{1}$, \\ Hongfei Meng ${ }^{1}$ and Rong Guo ${ }^{1}$ \\ 1 College of Geography and Environmental Science, Northwest Normal University, Lanzhou 730070, China; \\ qx888@nwnu.edu.cn (X.Q.); wangshengjie@nwnu.edu.cn (S.W.); 2015211658@nwnu.edu.cn (R.C.); \\ 2016211720@nwnu.edu.cn (H.M.); 2017212149@nwnu.edu.cn (R.G.) \\ 2 Laboratory of Atmospheric Physics, University of Patras, GR 26500 Patras, Greece; athanarg@upatras.gr \\ 3 State Key Laboratory of Cryospheric Sciences, Northwest Institute of Eco-Environment and Resources, \\ Chinese Academy of Sciences, Lanzhou 730000, China \\ * Correspondence: mjzhang@nwnu.edu.cn
}

Received: 13 March 2019; Accepted: 10 April 2019; Published: 13 April 2019

\begin{abstract}
Hydrological processes produce effects on water resources in inland mountainous regions. To perform a comprehensive investigation of the important segments of the water cycle, using the Qilian Mountains as a case study, precipitation, soil, plant, river, and groundwater were collected during the plant growing season of 2016. All samples were collected on a monthly basis, except precipitation, which was collected on a per event basis. The results showed that: the "temperature effect" was apparent, which suggested a drier climate background; there were differences in the slope and intercept of the local meteoric water line, using different regression methods; and the $\delta^{18} \mathrm{O}$ of soil water varied greatly in the topsoil, tended to be similar in the deep soil, and became increasingly depleted as the soil depth increased. The responses of the soil water isotopes to precipitation pulses had different boundaries. The major water source for Caragana Fabr. in no-precipitation month was located in the 0-30 cm soil layer, but was different in months when precipitation occurred. Overall, the findings from the stable isotopes provide insights into hydrological processes and offer a platform to understand mountainous water cycle in arid areas.
\end{abstract}

Keywords: Qilian Mountains; stable isotopes; Iso Source; growth season; water uptake

\section{Introduction}

As componets of the water molecule, the stable isotopes ${ }^{18} \mathrm{O}$ and ${ }^{2} \mathrm{H}(\mathrm{D})$ are useful tracers to describe regional water cycle because they reveal information about hydrological processes including precipitation, infiltration, evaporation, and transpiration [1]. In spite of their low abundance in nature, these heavy isotopes are sensitive to changes in climate and hydrology. The stable isotopes of different water bodies can be used to investgate atmospheric moisture transport [2,3], plant water sources and water use patterns [4-6], recharge mechanisms and transport of soil water [7,8], runoff generation and confluence [9,10], and recharge source and groundwater mechanisms [11,12], etc. Thus, stable isotopes are popular in hydrological and climatic study.

The Qilian Mountains are located in the northeastern edge of the Tibetan Plateau. Lofty mountains and deep valleys occur in a staggered formation, which creates a special geographic position. The mountains are the headwaters of the Shiyang, Heihe, Shule, and many other inland rivers. Therefore, the Qilian Mountains may be considered a "wet island" in the western Gobi desert, and are the water source of the Hexi Corridor oasis. They also play a crucial role in the ecological balance of the Badain Jaran and Tengger deserts. Due to the development of stable isotope research techniques in recent decades, 
stable isotopes in water bodies have been studied for different areas of the Qilian Mountains [5,13-17]. However, a comprehensive investigation of the different water bodies, from precipitation to surface, soil, and plant waters (sometimes known as soil-plant-atmosphere continuum, SPAC), is still limited, since most isotope sampling studies have only been conducted once or over a very short period of time. In this study three sites were selected: one located on a north-facing slope, the second on a south-facing slope, and the third on the mountain ridge. Soils, plants, river water, and groundwater were sampled during the growing season (i.e., from May to September), while precipitation was sampled throughout the complete year. $\delta^{18} \mathrm{O}$ and $\delta^{2} \mathrm{H}$ were measured in order to trace a series of key parameters of the water cycle process in this arid mountainous area, extract baseline information, and study the variations in precipitation and other water isotope characteristics.

The objective of this work is to analyze: (1) the applicability of different local meteoric water line (LMWL) regressions compared to the most commonly used method (ordinary least squares regression, OLSR); (2) the variation in isotopic profiles for soil water at different sites and its influencing factors; (3) how plants use the soil water from different depths in an arid mountainous area, and whether soil water use is the same for one type of plant grown at different sites; (4) the water recharge connection between precipitation, river water, and groundwater; and (5) the relationship of the above-mentioned water bodies from an isotopic perspective. From this information, we can describe the characteristics and interactions of stable isotopes of different water bodies, and provide a reference for the research of water cycle processes in similar mountainous regions outside China.

\section{Materials and Methods}

\subsection{Study Area}

The Qilian Mountains $\left(93^{\circ} 30^{\prime}-103^{\circ} \mathrm{E}, 36^{\circ} 30^{\prime}-39^{\circ} 30^{\prime} \mathrm{N}\right)$ are located in the northeastern edge of the Tibetan Plateau. They are a geosyncline originating in the Paleozoic era that later formed a fold belt due to Caledonian and Variscan orogeny. They consist of several parallel mountains and valleys, about $850 \mathrm{~km}$ long and 200-300 km wide, resulting from the movement of fault blocks beginning in the Cretaceous period. The altitude of the ridges ranges between 4000 and $6000 \mathrm{~m}$. Mountains higher than $4000 \mathrm{~m}$ are covered perennially with snow and develop glaciers. Many rivers originate from these mountains and, hence, they are known as the solid water reservoirs of the high mountains. The climate of the Qilian Mountains is either temperate or semi-arid, since it is affected by the continental and the plateau climates. In the cold climate region, winter is long and summer is short, where the average annual temperature is below $4{ }^{\circ} \mathrm{C}$ (below $-11^{\circ} \mathrm{C}$ in January and below $15^{\circ} \mathrm{C}$ in July). The annual mean precipitation amounts decrease from $700 \mathrm{~mm}$ at the south slope to $400 \mathrm{~mm}$ at the north slope. The Qilian Mountains are the headwaters of many rivers of the Hexi Corridor, hence, they are extremely important for this region. As a result of the complex natural conditions and large differences in water-heat conditions of the region, plenty of vegetation species can be found here, and many soil types have been formed, with obvious vertical gradients and horizontal differences. The main soil types found here are alpine cold desert soil, alpine meadow soil, mountain meadow soil, gray cinnamon soil, chernozem, chestnut soil, etc. The vertical vegetation belt, starting at a height of $2000 \mathrm{~m}$, consists mainly of desert steppe belt, steppe belt, forest steppe belt, shrub steppe belt, meadow steppe belt, snow belt, etc. During our spatially-intensive sampling, water samples for isotopic analysis were collected at three locations covering the north slope (Gulang), the south slope (Tianzhu), and the mountain ridge (Wushaoling) (Figure 1 and Table 1). During our temporally-intensive sampling, the one-year precipitation samples were collected on an event basis. All other samples were collected monthly throughout the growing season. 


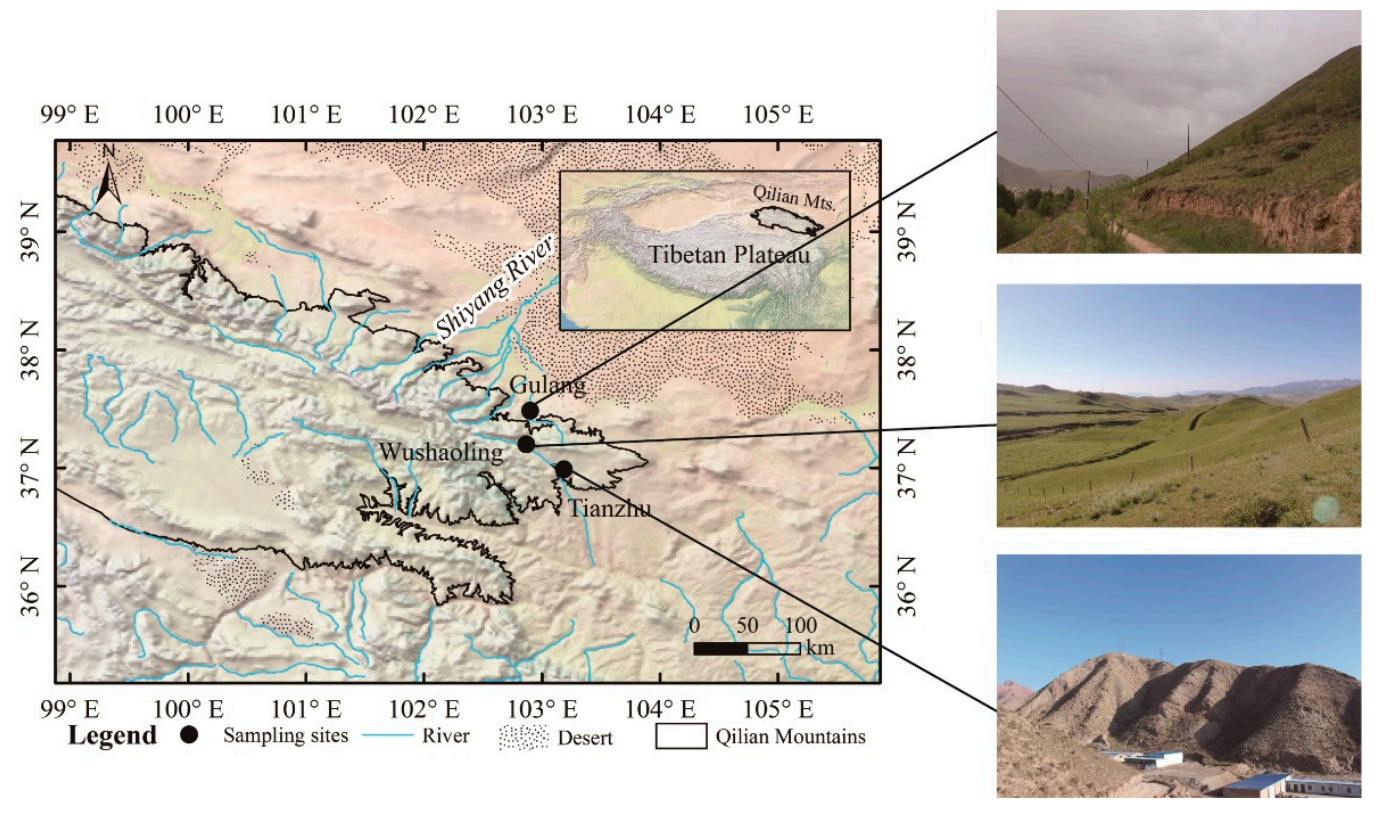

Figure 1. A map showing the locations of the sampling sites in the Qilian Mountains. The boundary of the mountainous area is marked by the black line. The satellite-derived background was acquired from Natural Earth (http://www.naturalearthdata.com). The desert areas are based on Wang et al. [18]. The inset map identifies the location of the Qilian Mountains relative to the Tibetan Plateau.

Table 1. The locations and long term climatology $(T=$ air temperature and $P=$ precipitation amount) during 1981-2010 at the sampling sites in the Qilian Mountains.

\begin{tabular}{cccccc}
\hline Sampling Sites & Latitude & Longitude & Altitude $(\mathbf{m})$ & $\boldsymbol{T}\left({ }^{\circ} \mathbf{C}\right)$ & $\boldsymbol{P}(\mathbf{m m})$ \\
\hline Gulang & $37^{\circ} 29^{\prime}$ & $102^{\circ} 54^{\prime}$ & 2072.4 & 5.7 & 352.3 \\
Wushaoling & $37^{\circ} 12^{\prime}$ & $102^{\circ} 52^{\prime}$ & 3045.1 & 0.3 & 407.4 \\
Tianzhu & $36^{\circ} 59^{\prime}$ & $103^{\circ} 11^{\prime}$ & 2484.8 & 3.5 & 450.0 \\
\hline
\end{tabular}

\subsection{Sampling and Data}

Precipitation samples were collected by the meteorological stations' personnel in 2016. Precipitation was collected in a clean, large caliber container, positioned on flat ground before the start of each precipitation event, and stored in either plastic bags and plastic bottles. Solid precipitation samples were sealed in plastic bags, left to melt at room temperature, and transferred into bottles and sealed. Liquid precipitation samples were directly stored in bottles and sealed. At the same time, relevant meteorological parameters (air temperature, relative humidity, precipitation amount, etc.) were recorded.

During the growing season, from May to September 2016, we collected soil, plant, river water, and groundwater samples at the three sites in the Qilian Mountains. Samples were collected on a monthly basis. Soil samples were collected by digging a soil pit $(1 \mathrm{~m} \times 1 \mathrm{~m} \times 1 \mathrm{~m})$, and collecting samples at every $10 \mathrm{~cm}$ vertical interval. The topsoil sampling began at $2 \mathrm{~cm}$ below the surface, in order to avoid samples biased from continuous exposure to the free atmosphere.

A representative plant (Caragana Fabr.) was selected for plant xylem sampling. We collected branches of about $0.3-0.5 \mathrm{~cm}$ in diameter and $3-5 \mathrm{~cm}$ long, put the xylem into sample bottles after removing the bark and phloem, and sealed the bottles.

When collecting river water and groundwater (well or spring water), we first rinsed the sample bottle 3 times with the river water or groundwater, collected water from a few centimeters below the surface (in order to ensure that the water was fully mixed and to avoid evaporation of the surface water, causing isotope fractionation) into the sample bottle, and sealed it. 
In total, 896 samples were collected (excluding repeat samples, Table 2). All samples were numbered and labeled according to its type when collected; the date and meteorological and environmental parameters were also recorded. To avoid isotope fractionation caused by evaporation, all samples were sealed immediately using insulation tape. Soil and plant samples were frozen, and the water samples were refrigerated.

Table 2. Number of samples collected in the Qilian Mountains from 2015 to 2016.

\begin{tabular}{cccccc}
\hline Sampling Sites & Precipitation & Plant & Soil & River & Groundwater \\
\hline Gulang & 60 & 15 & 165 & 5 & 5 \\
Wushaoling & 156 & 20 & 165 & 5 & 5 \\
Tianzhu & 107 & 13 & 165 & 5 & 5 \\
\hline
\end{tabular}

Soil and plant water were extracted using the automatic water extraction system LI-2100 (LICA United Technology Limited, Beijing, China). The $\delta^{18} \mathrm{O}$ and $\delta^{2} \mathrm{H}$ of soil water, stem water, precipitation, river water, and groundwater were measured using the liquid-water isotope analyzer DLT-100 (Los Gatos Research, CA, USA) at the Stable Isotope Laboratory, College of geography and environmental science, Northwest Normal University. The ratio of ${ }^{18} \mathrm{O} /{ }^{16} \mathrm{O}$ and ${ }^{2} \mathrm{H} / \mathrm{H}$ isotopes in water samples were measured accurately and expressed as $\delta^{18} \mathrm{O}$ and $\delta^{2} \mathrm{H}$, relative to the Vienna Standard Mean Ocean Water (V-SMOW) using,

$$
\begin{aligned}
& \delta^{18} \mathrm{O}=\left[\frac{R_{\text {sample }}}{R_{\text {standard }}}-1\right] \times 1000 \% 0 \\
& \delta^{2} \mathrm{H}=\left[\frac{R_{\text {sample }}}{R_{\text {standard }}}-1\right] \times 1000 \% 0
\end{aligned}
$$

where $R_{\text {sample }}$ is the ratio of ${ }^{18} \mathrm{O} /{ }^{16} \mathrm{O}\left(\right.$ or $\left.{ }^{2} \mathrm{H} / \mathrm{H}\right)$ in the water sample, and $R_{\text {standard }}$ is the ratio of ${ }^{18} \mathrm{O} /{ }^{16} \mathrm{O}$ $\left({ }^{2} \mathrm{H} / \mathrm{H}\right)$ in the V-SMOW. The measurement accuracy for $\delta^{18} \mathrm{O}$ and $\delta^{2} \mathrm{H}$ is $0.3 \%$ and $1 \%$, respectively.

Each sample and standard sample was injected and sequentially analyzed 6 times using a microliter syringe. The results of the first two analyses were discarded since these were performed in order to eliminate any residual water and instrument memory. The final result for each sample was the mean of the measurements based on the last four injections. Quality control was performed via the LWIA Post Analysis (version 3.1.0.9) software, developed by Los Gatos Research (LGR), Inc. (San Jose, CA, USA). The isotope standards used were provided by Los Gatos Research, Inc. According to the isotope ratio range of our samples, three standards were selected from the five LGR standards (expressed relative to the V-SMOV), which include for $\delta^{2} \mathrm{H}$ and $\delta^{18} \mathrm{O}$, respectively: lgr1a: $-154.30 \%$ o and $-19.50 \%$, lgr2a: $-123.60 \%$ ond $-16.14 \%$ o, lgr3a: $-96.40 \%$ o and $-13.10 \%$, lgr4a: $-51.00 \%$ ond $-7.69 \%$, and lgr5a: $-9.50 \%$ ond $-2.80 \%$ o. The complete protocol for the analysis was provided by Los Gatos Research, Inc.

Soil water content (SWC) was calculated by measuring each sample's wet weight immediately after unsealing it, drying the samples at $105{ }^{\circ} \mathrm{C}$ until the weight stabilized, and then measuring the soil's dry weight.

\subsection{LWML Regressions}

The relationship between $\delta^{2} \mathrm{H}$ and $\delta^{18} \mathrm{O}$ in precipitation at a certain site, known as the local meteoric water line (LMWL), is commonly determined using the ordinary least squares regression (OLSR), which gives equal weighting to each sample [19]. Alternatively, reduced major axis (RMA) regression and major axis (MA) regression can be used to determine LMWL without precipitation weighting $[19,20]$. More recently, a new precipitation-weighted least squares regression method (PWLSR) was proposed by Hughes and Crawford [21], with corresponding amount-weighted regressions defined by Crawford et al. [20]: precipitation-weighted reduced major axis (PWRMA) 
regression and precipitation-weighted major axis (PWMA) regression. All these six regressions can be calculated using the Local Meteoric Water Line Freeware software [20].

\subsection{IsoSource Model}

IsoSource is a procedure developed by Phillips, to calculate the range of all possible source contributions for a mixture when the number of potential sources is greater than $n+1$. It has to satisfy the isotope quality conservation [22]:

$$
\left\{\begin{array}{c}
\delta^{2} \mathrm{H}=f_{1} \delta^{2} \mathrm{H}_{1}+f_{2} \delta^{2} \mathrm{H}_{2}+f_{3} \delta^{2} \mathrm{H}_{3}+\ldots \ldots \\
\delta^{18} \mathrm{O}=f_{1} \delta^{18} \mathrm{O}_{1}+f_{2} \delta^{18} \mathrm{O}_{2}+f_{3} \delta^{18} \mathrm{O}_{3}+\ldots \ldots \\
f_{1}+f_{2}+f_{3}+\ldots \ldots=1
\end{array}\right.
$$

where $\delta^{2} \mathrm{H}$ and $\delta^{18} \mathrm{O}$ are the ratios of the stable hydrogen and oxygen isotope in stem water, $\delta^{2} \mathrm{H}_{1}$ $\left(\delta^{18} \mathrm{O}_{1}\right), \delta^{2} \mathrm{H}_{2}\left(\delta^{18} \mathrm{O}_{2}\right), \delta^{2} \mathrm{H}_{3}\left(\delta^{18} \mathrm{O}_{3}\right), \delta^{2} \mathrm{H}_{n}\left(\delta^{18} \mathrm{O}_{n}\right)$ are the ratios of the stable hydrogen and oxygen isotope in $n$ different water sources, and $f_{1}, f_{2}, f_{3}, \ldots \ldots, f_{n}$ are the proportions of $n$ water sources in the total amount of stem water.

\section{Results}

\subsection{Stable Isotopes in Different Water Bodies}

\subsubsection{Precipitation}

The basic information about $\delta^{18} \mathrm{O}$ and $\delta^{2} \mathrm{H}$ in precipitation at the three sites are presented (Table 3 ). The differences in the mean $\delta^{18} \mathrm{O}, \delta^{2} \mathrm{H}$, and D-excess (i.e., $\delta^{2} \mathrm{H}-8 \delta^{18} \mathrm{O}$ ) [23] among these sites were small, with the greatest $\delta^{18} \mathrm{O}$ and $\delta^{2} \mathrm{H}$ values found in Tianzhu, suggesting a more intense under-cloud evaporation during precipitation. The mean D-excess values at the three sites were all higher than that of the Global Meteoric Water Line (GMWL, i.e., 10). This finding was in accordance with the meteorological conditions of the area, which are characterized by low relative humidity and strong evaporation under kinetic fractionation [14]. The correlation and regression relationship between $\delta^{18} \mathrm{O}$ and precipitation, and between $\delta^{18} \mathrm{O}$ and temperature are showed in Table 4. The "amount effect" was not significant in the Qilian Mountains, but the "temperature effect" was apparent, which suggested evaporation enrichment.

Table 3. Isotopic signatures of precipitation in the Qilian Mountains from 2015 to 2016.

\begin{tabular}{|c|c|c|c|}
\hline & $\delta^{18} \mathrm{O}(\% \mathrm{o})$ & $\delta^{2} \mathrm{H}(\% \mathrm{o})$ & D-Excess (\%o) \\
\hline Gulang & $\begin{array}{c}-19.91-2.40 \\
(\text { mean }-8.58)\end{array}$ & $\begin{array}{l}-135.86-14.28 \\
(\text { mean }-54.21)\end{array}$ & $\begin{array}{c}-10.96-29.41 \\
(\text { mean } 14.46)\end{array}$ \\
\hline Wushaoling & $\begin{array}{c}-31.11-2.58 \\
(\text { mean }-8.61)\end{array}$ & $\begin{array}{l}-232.15-28.64 \\
(\text { mean }-54.78)\end{array}$ & $\begin{array}{l}-8.77-31.43 \\
(\text { mean } 14.10)\end{array}$ \\
\hline Tianzhu & $\begin{array}{c}-19.67-7.89 \\
(\text { mean }-7.53)\end{array}$ & $\begin{array}{l}-158.44-60.81 \\
(\text { mean }-48.48)\end{array}$ & $\begin{array}{c}-10.01-31.46 \\
\text { (mean } 11.79 \text { ) }\end{array}$ \\
\hline
\end{tabular}

Craig [24], using 400 precipitation samples from around the globe, found that there is linear relationship between $\delta^{2} \mathrm{H}$ and $\delta^{18} \mathrm{O}$, called the Global Meteoric Water Line (GMWL), where $\delta^{2} \mathrm{H}=8 \delta^{18} \mathrm{O}$ +10 . The line calculated using samples collected at a specific region, called the Local Meteorological Water Line (LMWL), often deviates from the GMWL due to different climatic and geographical factors (water vapor sources, air humidity, water vapor path, temperature, altitude, etc.).

The LMWL of the three sampling sites, using six regressions (OLSR, MA, RMA, PWLSR, PWMA, PWRMA), are presented in Figure 2. The slope differences calculated among the various regression methods were the least for Wushaoling, followed by Tianzhu, with the largest differences in slope 
at Gulang. Crawford et al. [20] suggested that the differences in slope, when calculated by different regressions, were smaller for sites where a positive correlation existed between the precipitation amount and $\delta^{18} \mathrm{O}$. However, the conditions in the Qilian Mountains were not like this: the precipitation "amount effect" was not significant here, but the "temperature effect" was apparent (Table 4). The correlation coefficient between $\delta^{18} \mathrm{O}$ and temperature was the smallest in Gulang, corresponding to the largest slope differences among various regressions. For unweighted regressions, the slope and intercept produced by OLSR were the smallest, and the greatest was produced by MA for all sites, so did the precipitation-weighted methods (Table 5).

Table 4. The relationship between $\delta^{18} \mathrm{O}$ and precipitation amount $(P)$, and between $\delta^{18} \mathrm{O}$ and temperature $(T)$.

\begin{tabular}{|c|c|c|c|c|}
\hline \multirow[b]{2}{*}{ Site } & \multicolumn{2}{|r|}{$\delta^{18} \mathrm{O}-P$} & \multicolumn{2}{|r|}{$\delta^{18} \mathrm{O}-T$} \\
\hline & $\begin{array}{l}\text { Correlation } \\
\text { Coefficient }\end{array}$ & $\begin{array}{l}\text { Regression Coefficient } \\
\left(\% \circ \cdot \mathrm{mm}^{-1}\right)\end{array}$ & $\begin{array}{l}\text { Correlation } \\
\text { Coefficient }\end{array}$ & $\begin{array}{l}\text { Regression Coefficient } \\
\left(\%_{\circ} \cdot{ }^{\circ} \mathrm{C}^{-1}\right)\end{array}$ \\
\hline Gulang & -0.15 & $\begin{array}{c}-0.11 \\
P=0.397>0.05\end{array}$ & $0.402 *$ & $\begin{array}{c}0.124 \\
P=0.017<0.05\end{array}$ \\
\hline Wushaoling & 0.095 & $\begin{array}{c}0.113 \\
P=0.289>0.05\end{array}$ & $0.483^{* *}$ & $\begin{array}{c}0.226 \\
P=0.000\end{array}$ \\
\hline Tianzhu & -0.096 & $\begin{array}{c}-0.066 \\
P=0.367>0.05\end{array}$ & $0.562 * *$ & $\begin{array}{c}0.362 \\
P=0.000\end{array}$ \\
\hline
\end{tabular}

${ }^{*}$ means statistically significant at the 0.05 level. ${ }^{* *}$ means statistically significant at the 0.01 level.
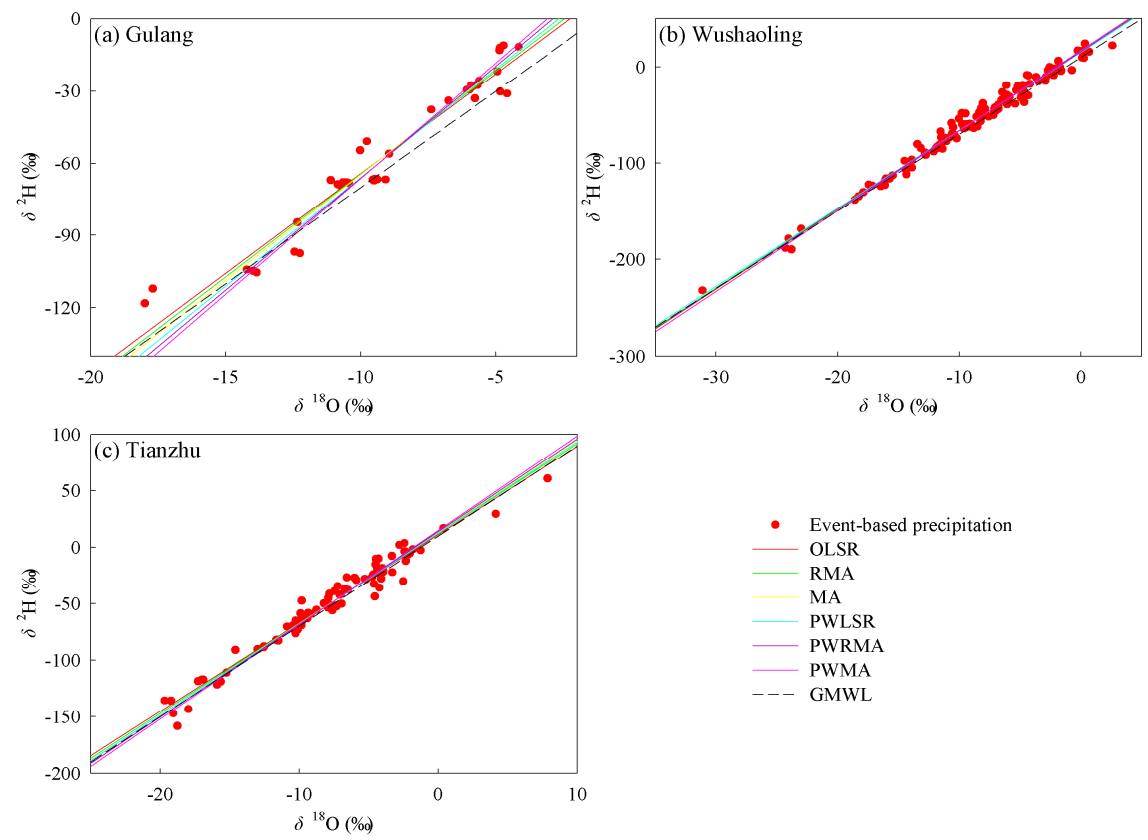

- Event-based precipitation

- OLSR

- RMA

MA

PWLSR

- PWRMA

PWMA

- GMWL

Figure 2. The Local Meteorological Water Line (LMWL) at the three sites; the Global Meteoric Water Line (GMWL) was also shown for reference. (a-c) are the LMWL at Gulang, Wushaoling, and Tianzhu, respectively. 
Table 5. Parameters of the fit for OLSR (ordinary least squares regression), RMA (reduced major axis regression), MA (major axis regression), PWLSR (precipitation weighted least squares regression), PWRMA (precipitation weighted reduced major axis regression), PWMA (precipitation weighted major axis regression) regressions at each site in the Qilian Mountains.

\begin{tabular}{cccccc}
\hline Sites & Algorithm & Slope & Intercept & rmSSEav & $t$-Value \\
\hline & OLSR & $8.31 \pm 0.32$ & $18.86 \pm 3.15$ & 1.01 & - \\
& RMA & $8.56 \pm 0.31$ & $21.17 \pm 3.08$ & 1.00 & 0.55 \\
Gulang N = 43 & MA & $8.81 \pm 0.33$ & $23.48 \pm 3.24$ & 1.01 & 1.09 \\
& PWLSR & $9.01 \pm 0.36$ & $24.24 \pm 3.55$ & 1.00 & 1.50 \\
& PWRMA & $9.31 \pm 0.37$ & $27.00 \pm 3.58$ & 1.03 & 2.07 \\
& PWMA & $9.60 \pm 0.37$ & $29.78 \pm 3.66$ & 1.08 & 2.59 \\
\hline & OLSR & $8.09 \pm 0.10$ & $14.99 \pm 1.02$ & 1.00 & - \\
Wushaoling N $=\mathbf{1 2 7}$ & RMA & $8.17 \pm 0.10$ & $15.64 \pm 1.02$ & 1.00 & 0.54 \\
& MA & $8.24 \pm 0.10$ & $16.27 \pm 1.03$ & 1.00 & 1.06 \\
& PWLSR & $8.09 \pm 0.12$ & $15.21 \pm 1.11$ & 1.00 & 0.01 \\
& PWRMA & $8.21 \pm 0.12$ & $16.15 \pm 1.12$ & 1.00 & 0.84 \\
& PWMA & $8.32 \pm 0.13$ & $17.07 \pm 1.13$ & 1.01 & 1.65 \\
\hline & OLSR & $7.83 \pm 0.16$ & $11.18 \pm 1.45$ & 1.01 & - \\
Tianzhu N $=\mathbf{9 0}$ & RMA & $7.96 \pm 0.15$ & $12.22 \pm 1.43$ & 1.00 & 0.61 \\
& MA & $8.10 \pm 0.16$ & $13.25 \pm 1.47$ & 1.01 & 1.21 \\
& PWLSR & $8.05 \pm 0.17$ & $12.60 \pm 1.56$ & 1.00 & 1.01 \\
& PWRMA & $8.20 \pm 0.17$ & $13.89 \pm 1.57$ & 1.01 & 1.68 \\
& PWMA & $8.35 \pm 0.17$ & $15.17 \pm 1.59$ & 1.03 & 2.32 \\
\hline
\end{tabular}

$\mathrm{N}$ is the number of data points used in the regression, rmSSEav is the average value of root mean sum of squared error and $t$-value is a value used in a $t$-test of the significance in the difference of each regression to that of OLSR.

\subsubsection{Soil Water}

Figure 3 presents the isotopic profile and soil water content (SWC) as a function of depth $(0-100 \mathrm{~cm})$ during the growing season (May to September). $\delta^{18} \mathrm{O}$ in soil water was mainly influenced by mixing with precipitation and evaporation [25]. Evaporation from the topsoil during dry intervals between rain events, resulted in heavy isotope enrichment of the residual water. $\delta^{18} \mathrm{O}$ in soil water changed significantly in the topsoil and tended to remain constant in the deep soil. From the vertical profile of $\delta^{18} \mathrm{O}$ in soil water (Figure 3), it can be seen that isotope values became increasingly depleted as soil depth increased. This is explained by the fact that topsoil is directly influenced by, and responds quickly to, precipitation, thus modifying the $\delta^{18} \mathrm{O}$ values. The isotope values in deep soil, which mix with topsoil water during the infiltration of precipitation, represent a hysteresis response. The intra-seasonal variation in isotope values was more pronounced at Gulang and Tianzhu, rather than at Wushaoling, depending on the month and location, likely reflecting the variation in the isotopic signatures of precipitation, as indicated by topsoil water content. These variations were reduced as $\delta^{18} \mathrm{O}$ became increasingly depleted with soil depth.

The $\delta^{18} \mathrm{O}$ values of soil water in Gulang and Tianzhu were higher during the summer (June-August) when compared to the rest of the year. This was due to the higher temperature that increased evaporation of soil moisture after precipitation, thus contributing to isotope enrichment. It should be noted that the $\delta^{18} \mathrm{O}$ in soil water in Wushaoling varied significantly in the $0-70 \mathrm{~cm}$ depth, which indicated that precipitation infiltrated the soil up to this depth. Wushaoling is located in a mountain area at the boundary between the monsoon and the non-monsoon zones (between the arid and semi-arid areas), and consequently has an abundant rainfall.

The monthly mean soil water isotope values, weighted by SWC, were calculated, the measured near-surface temperature values were recorded, and any precipitation events one week before sampling were also marked (Figure 4). The changes in monthly $\delta^{18} \mathrm{O}$ and $\delta^{2} \mathrm{H}$ were minor, but soil temperature obviously changed. These changes showed that temperature was not the sole factor that impacted soil water isotopes, but that some other factors, like vegetation coverage, also played a part. 

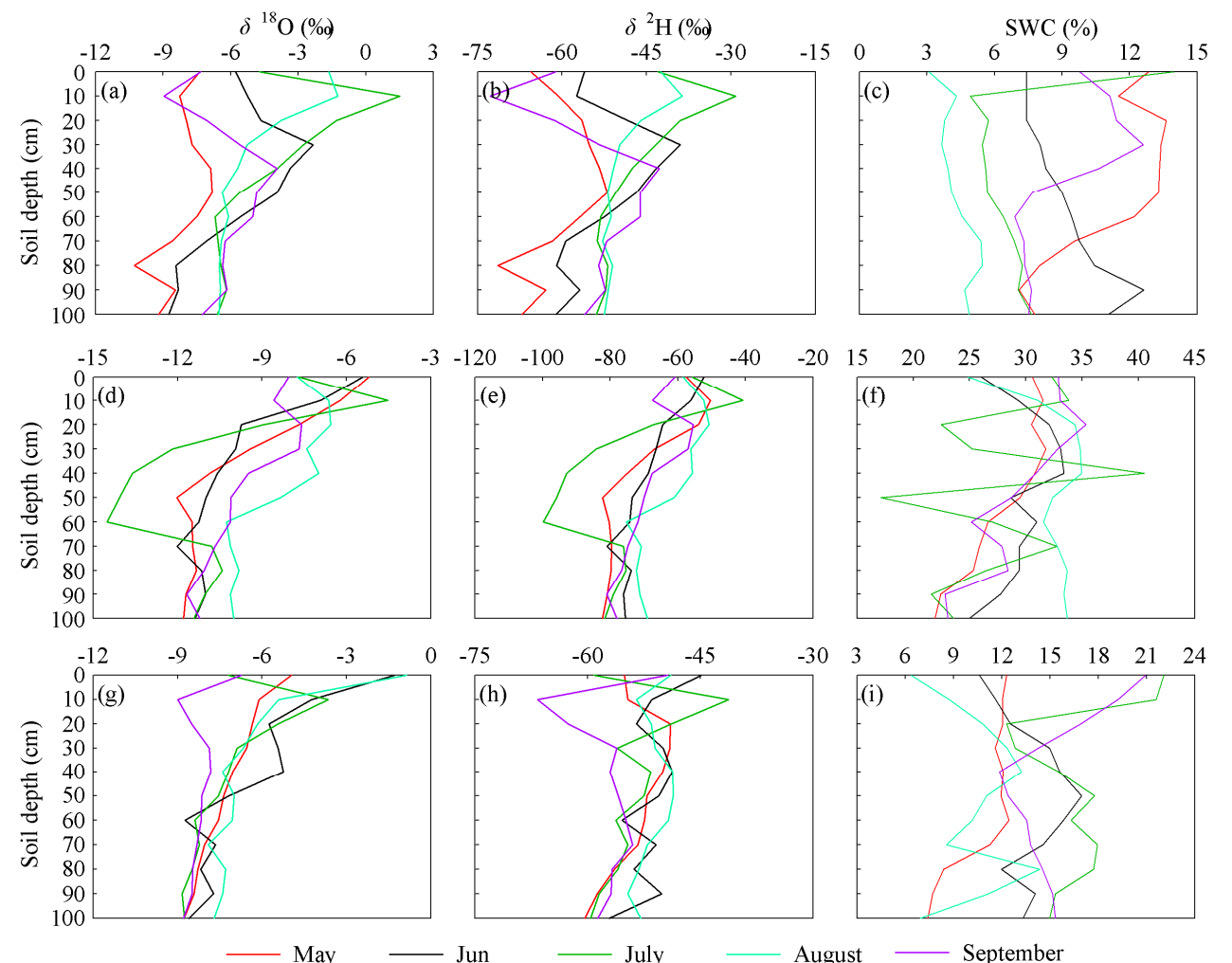

Figure 3. Mean $\delta^{18} \mathrm{O}, \delta^{2} \mathrm{H}$, and soil water content (SWC) for soil water at a depth of $0-100 \mathrm{~cm}$ in Gulang $(\mathbf{a}-\mathbf{c})$, Wushaoling $(\mathbf{d}-\mathbf{f})$ and Tianzhu $(\mathbf{g}-\mathbf{i})$.
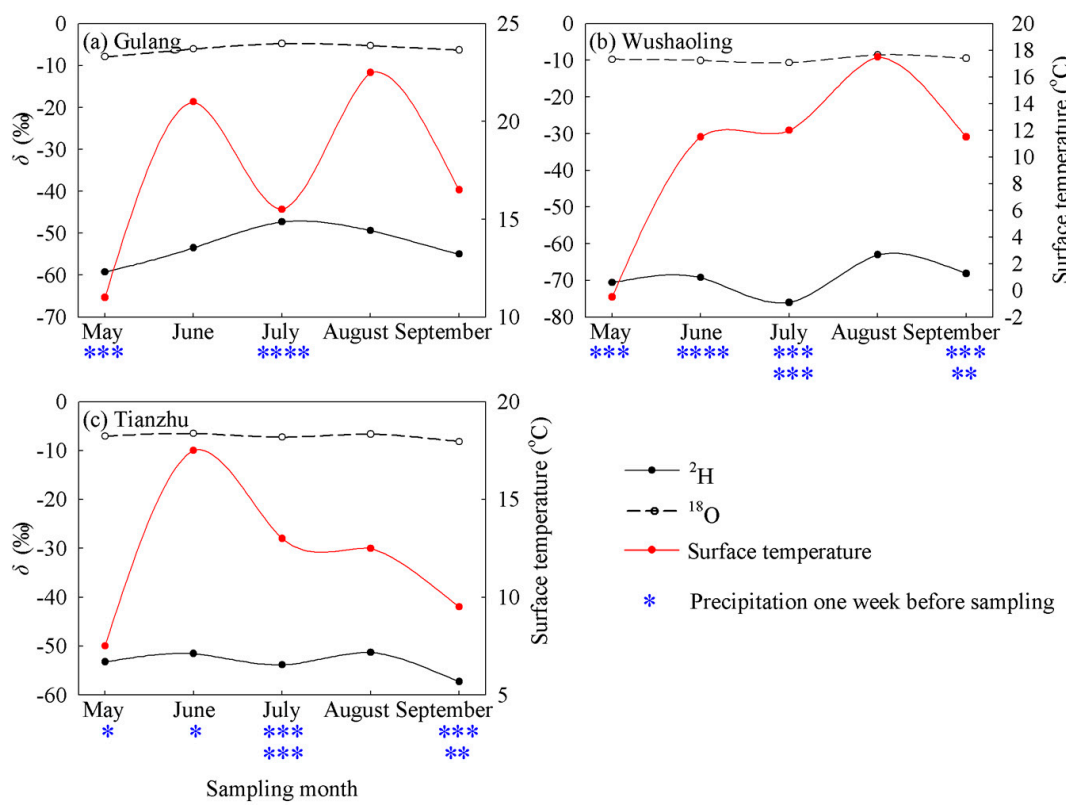

$-{ }^{2} \mathrm{H}$

$\rightarrow-{ }^{18} \mathrm{O}$

$\rightarrow$ Surface temperature

* Precipitation one week before sampling

Figure 4. Monthly variation of SWC-weighted soil water $\delta^{18} \mathrm{O}$ and $\delta^{2} \mathrm{H}$, and near-surface temperature. $(\mathbf{a}-\mathbf{c})$ are the variations at Gulang, Wushaoling and Tianzhu, respectively.

The correlation coefficients between $\delta^{18} \mathrm{O}$ and soil water content are provided in Table 6. Gulang and Tianzhu generally presented positive in May and negative correlation coefficients from June to September. This corresponded to the seasonal changes in precipitation amount. Frequent summer precipitation led to isotopic depleted rain infiltration into deeper soil. However, the infiltration process would decrease the extent of, or slow down the time of, evaporation. However, precipitation in May 
was less frequent and its amount was lower, therefore soil water could not infiltrate to deep soil layers because of intense evaporation. Consequently, with the increase in SWC, stable isotopes were enriched. On the contrary, the correlation coefficients for Wushaoling were positive in rainy July and August, and negative during the rest of the year. However, in months with frequent precipitation, the relative high temperature, single meadow vegetation, and loose soil texture still allowed for rapid evaporation.

Table 6. Correlation coefficients between soil water $\delta^{18} \mathrm{O}$ and soil water content (SWC).

\begin{tabular}{cccccc}
\hline Month & May & June & July & August & September \\
\hline Gulang & $0.781^{* *}$ & $-0.733^{*}$ & -0.291 & $-0.655^{*}$ & -0.057 \\
Wushaoling & -0.125 & -0.524 & 0.227 & $0.907^{* *}$ & $-0.709 *$ \\
Tianzhu & 0.589 & $-0.640^{*}$ & 0.040 & -0.571 & -0.024 \\
\hline${ }^{*}$ means statistically significant at the 0.05 level. ${ }^{* *}$ means statistically significant at the 0.01 level.
\end{tabular}

The sites that had multiple precipitation events in the one week period before sampling are used to discuss the response of soil water isotopes to precipitation pulses of different amounts (Wushaoling and Tianzhu) (Figure 5). The response of each layer's SWC to precipitation was positive: the SWC value increased after precipitation, and the higher the precipitation amount, the bigger the SWC value. While the response was different for the $\delta^{18} \mathrm{O}$ and $\delta^{2} \mathrm{H}$ of soil water, apparent boundaries existed in the different soil layers' response to precipitation. For Wushaoling, the variation could be classified into three boundaries: the 0-20 cm layer varied with SWC, the 30-60 cm layer had a reverse response, and the $70-100 \mathrm{~cm}$ layer had few changes. For Wushaoling, the variations in both $\delta^{18} \mathrm{O}$ and $\delta^{2} \mathrm{H}$ were classified into two boundaries: the $0-40 \mathrm{~cm}$ layer varied with precipitation amount, whereas the 50-100 cm layer changes were small. Hence, different sites had different responses to precipitation.
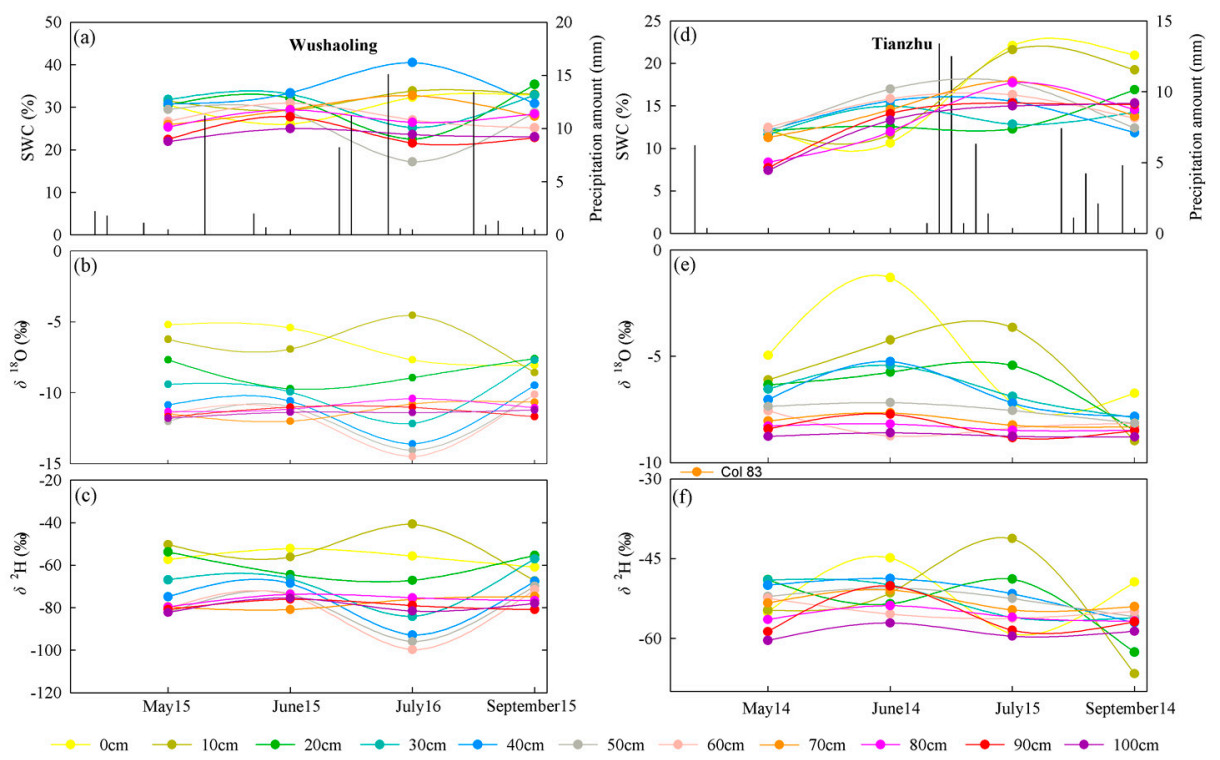

Figure 5. The response of soil water, $\delta^{18} \mathrm{O}$, and $\delta^{2} \mathrm{H}$ to different amounts. (a-c) are the response of SWC, $\delta^{18} \mathrm{O}$, and $\delta^{2} \mathrm{H}$ to precipitation pulsse at Wushaoling, and $(\mathbf{d}-\mathbf{f})$ are for the responses at Tianzhu.

\subsubsection{Groundwater and River Water}

Rivers in the Qilian Mountains are mainly derived from ice and snow melt, precipitation, and groundwater recharge, so their stable isotopes can reflect the characteristics of water sources and evaporation. The spatial and temporal differences in stable isotopes of river water are influenced by recharge source, season, stream segment, and evaporation. For groundwater, besides its recharge source, the recharge mechanism and the water table can also cause differences in stable isotopes. 
In terms of each site, the variation trend in $\delta^{18} \mathrm{O}$ and $\delta^{2} \mathrm{H}$ for river water and groundwater were generally consistent, and indicated a similar water source for the two water bodies (Figure 6). In most months, the isotope values of river water were higher than groundwater, which showed that river water experienced more evaporation due to its exposure to air. There was an intersection between the river water and groundwater sampled, which showed a water exchange and mutual-supply relationship (the intersection occurred in June at Gulang and Tianzhu, and in August at Wushaoling). The correlation analysis between amount-weighted precipitation, river water, and groundwater suggested that the proportion of river water sourced from precipitation was almost as much as that exchanged with groundwater (Table 7). However, the correlation coefficients between river water and groundwater at Wushaoling and Tianzhu were both high, which demonstrated a very strong hydraulic connection between river water and groundwater. Moreover, the means of $\delta^{18} \mathrm{O}$ and $\delta^{2} \mathrm{H}$ for the river water and groundwater in Tianzhu were greater than in Gulang and Wushaoling, which reflected a drier climate (Table 8).
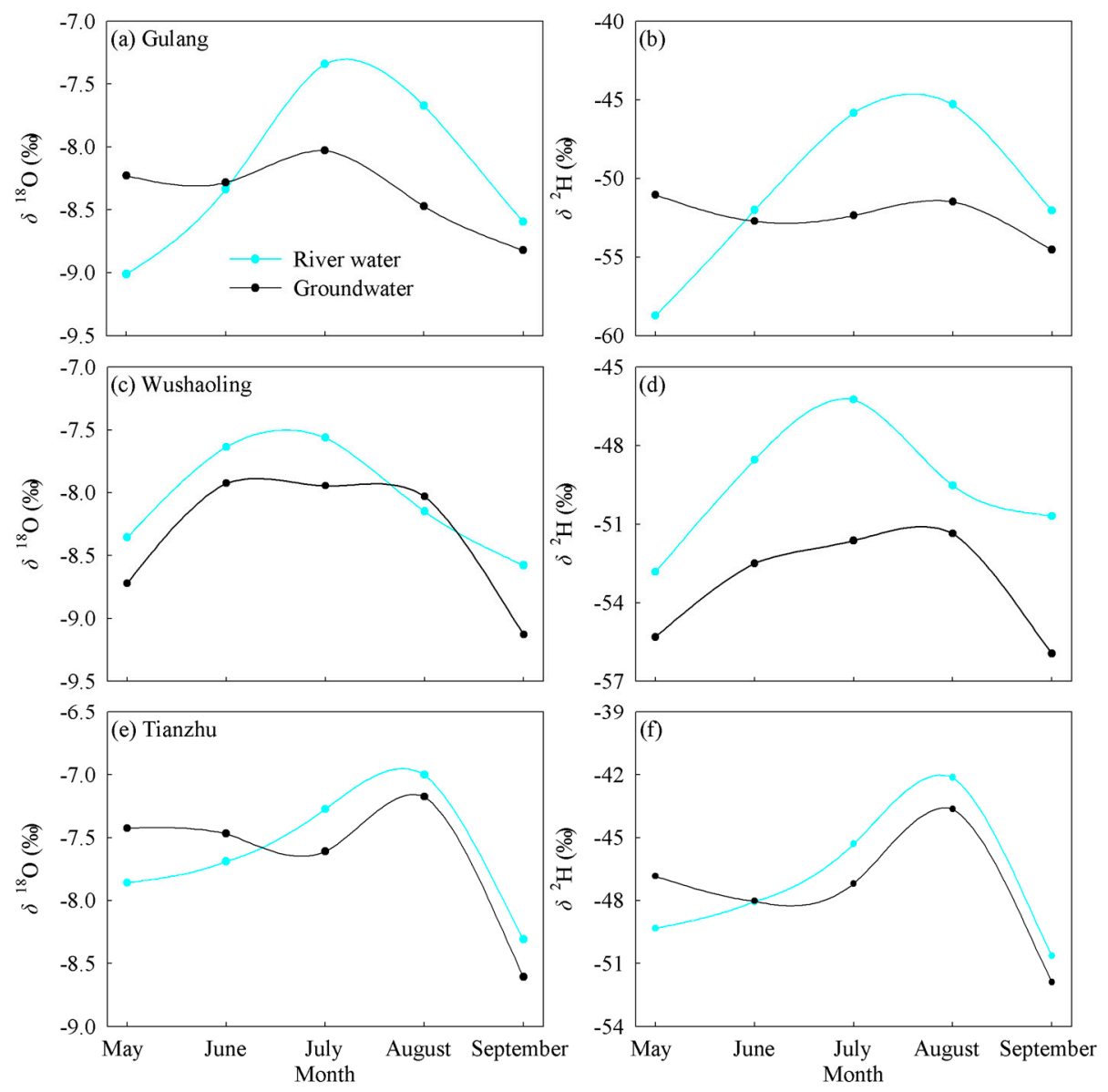

Figure 6. $\delta^{18} \mathrm{O}$ and $\delta^{2} \mathrm{H}$ in river water and groundwater where $(\mathbf{a}, \mathbf{b})$ are the $\delta^{18} \mathrm{O}$ and $\delta^{2} \mathrm{H}$ measurements, respectively, in river water and groundwater at Gulang; (c,d) are the measurements for Wushaoling; and $(\mathbf{e}, \mathbf{f})$ are the measurements for Tianzhu.

Table 7. The correlation relationships between precipitation, river water, and groundwater.

\begin{tabular}{cccc}
\hline Sites & Precipitation-River Water & Precipitation-Groundwater & River Water-Groundwater \\
\hline Gulang & 0.386 & 0.118 & 0.358 \\
Wushaoling & 0.413 & 0.142 & $0.893^{*}$ \\
Tianzhu & -0.455 & -0.398 & 0.798 \\
\hline
\end{tabular}

${ }^{*}$ means statistically significant at the 0.05 level. 
Table 8. The mean $\delta^{18} \mathrm{O}$ and $\delta^{2} \mathrm{H}$ for river water and groundwater.

\begin{tabular}{ccccc}
\hline \multirow{2}{*}{ Site } & \multicolumn{2}{c}{ River Water } & \multicolumn{2}{c}{ Groundwater } \\
\cline { 2 - 5 } & $\left.\delta^{\mathbf{1 8}} \mathbf{O} \mathbf{( \% o}\right)$ & $\delta^{\mathbf{2}} \mathbf{H ~ ( \% o )}$ & $\left.\delta^{\mathbf{1 8}} \mathbf{O} \mathbf{( \% o}\right)$ & $\delta^{\mathbf{2}} \mathbf{H ~ ( \% o )}$ \\
\hline Gulang & -8.19144 & -50.7811 & -8.36746 & -52.4299 \\
Wushaoling & -8.05623 & -49.566 & -8.34914 & -53.3473 \\
Tianzhu & -7.62581 & -47.0895 & -7.65622 & -47.5145 \\
\hline
\end{tabular}

\subsubsection{Relationships between the Isotope Signatures of Various Water Bodies}

Figure 7 shows the linear relationship between $\delta^{18} \mathrm{O}$ and $\delta^{2} \mathrm{H}$ in precipitation, soil water, stem water (the plant species collected are presented in Table 9), river water, and groundwater. The isotope values of the different water bodies at the three sites were generally all below the LMWL, i.e., more enriched when compared with the isotope values of precipitation, which indicated that all of the water sources sampled, especially soil and xylem water, had undergone evaporation.

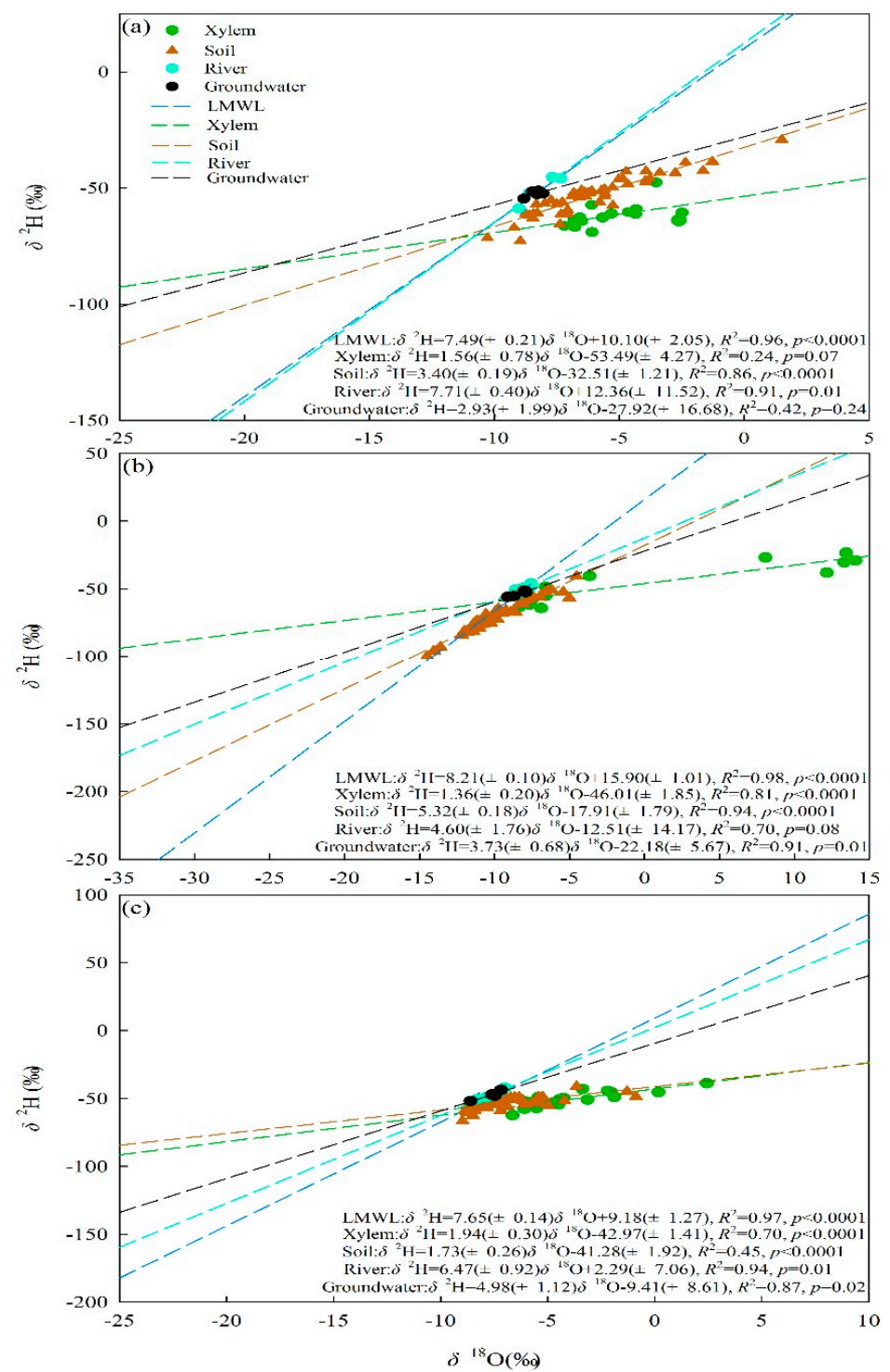

Figure 7. The linear relationship between $\delta^{18} \mathrm{O}$ and $\delta^{2} \mathrm{H}$ of the different water bodies sampled in (a) Gulang, (b) Wushaoling, and (c) Tianzhu. 
Table 9. Identification of the plant species collected in the Qilian Mountains in 2016.

\begin{tabular}{cc}
\hline Sampling Sites & Latin Name of Plant Species \\
\hline Gulang & Armeniaca vulgaris Lam. \\
Caragana korshinskii Kom. \\
Populus davidiana
\end{tabular}

The isotope values of the river water in Gulang (Figure 7a) were generally located along the LMWL, which indicated that river water came from local precipitation [5]. The groundwater and soil water isotope values were quite similar, which suggested a recharge connection. Few of the stem water values are close to soil water values, which meant that the direct contribution of soil water to plant water was low. Since plant sampling sites were far from the rivers and groundwater, we could not trace the other plant water sources. The isotope values for soil water and river water in Wushaoling (Figure $7 \mathrm{~b}$ ) were situated between those for precipitation and groundwater, which suggested that the soil and river water originate from both precipitation and groundwater recharge. In Tianzhu (Figure 7c), the isotope values for river water lay between those of precipitation and groundwater, which indicated that river water resulted from precipitation. The specific recharge relationship between river water and groundwater requires further research. Stem water isotope values coincided with those of soil water, and were rather distinct from those of precipitation, which indicated that stem water came mainly from soil water.

\subsection{The Fraction of Plant Water Uptake from Different Soil Depths}

\subsubsection{Isotopic Characteristics of Stem Water}

The variations in $\delta^{18} \mathrm{O}$ and $\delta^{2} \mathrm{H}$ for the stem water of a plant genus (Caragana Fabr.) common to all three sites were analyzed as a case study (Figure 8). The isotope values for both $\delta^{18} \mathrm{O}$ and $\delta^{2} \mathrm{H}$ were higher at south slope than the north slope and mountain locations, which indicated higher evaporation on the south slope. The variation in $\delta^{18} \mathrm{O}$ ranged between $-7.66 \%$ ond $-1.89 \%$, and was lower than that of $\delta^{2} \mathrm{H}$, which ranged between $-64.17 \%$ o and $-45.43 \%$, which suggested that the variation in $\delta^{18} \mathrm{O}$ was smaller than in $\delta^{2} \mathrm{H}$. The maximum value of $\delta^{18} \mathrm{O}$ was observed in Gulang and Tianzhu in September, and in Wushaoling in July. The maximum $\delta^{2} \mathrm{H}$ value was observed in Gulang and Wushaoling in July, and in Tianzhu in August, which indicated that, although water was extracted from the same plant species, their distinct isotopic signatures reflect the differences in location and climate.
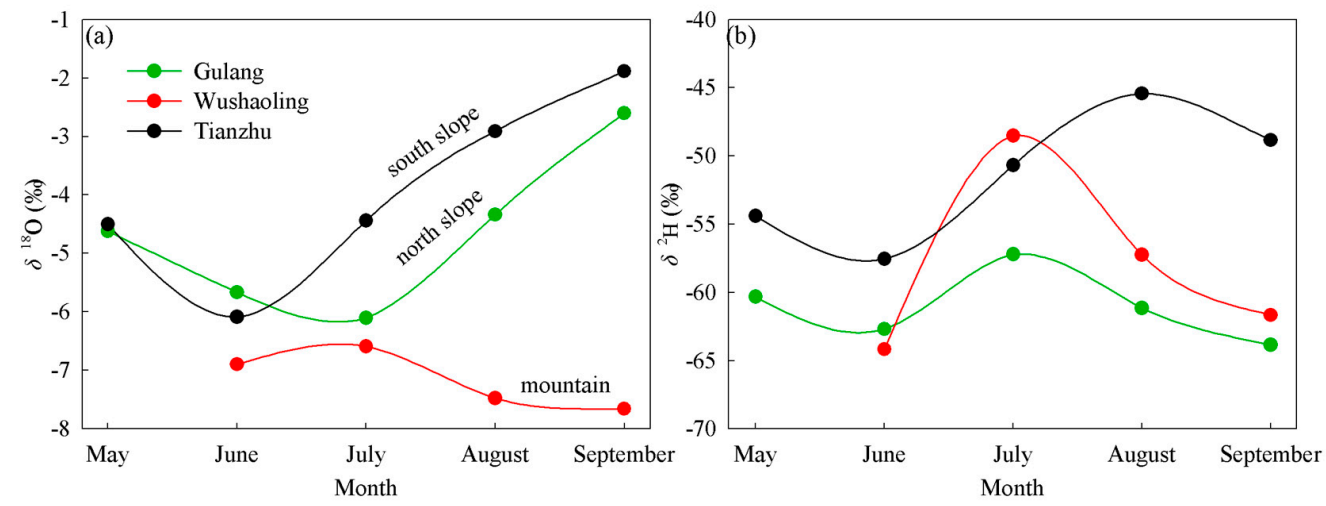

Figure 8. The monthly variations in stem water isotopes. (a) is $\delta^{18} \mathrm{O}$ variation and (b) is $\delta^{2} \mathrm{H}$ variation. 
The major meteorological parameters that were analyzed in order to explain the relationship between stem water stable isotopes and meteorological conditions (Figure 9). $\delta^{18} \mathrm{O}$ was generally negatively correlated with temperature, water vapor, and precipitation, whereas $\delta^{2} \mathrm{H}$ responded to the variation in relative humidity.
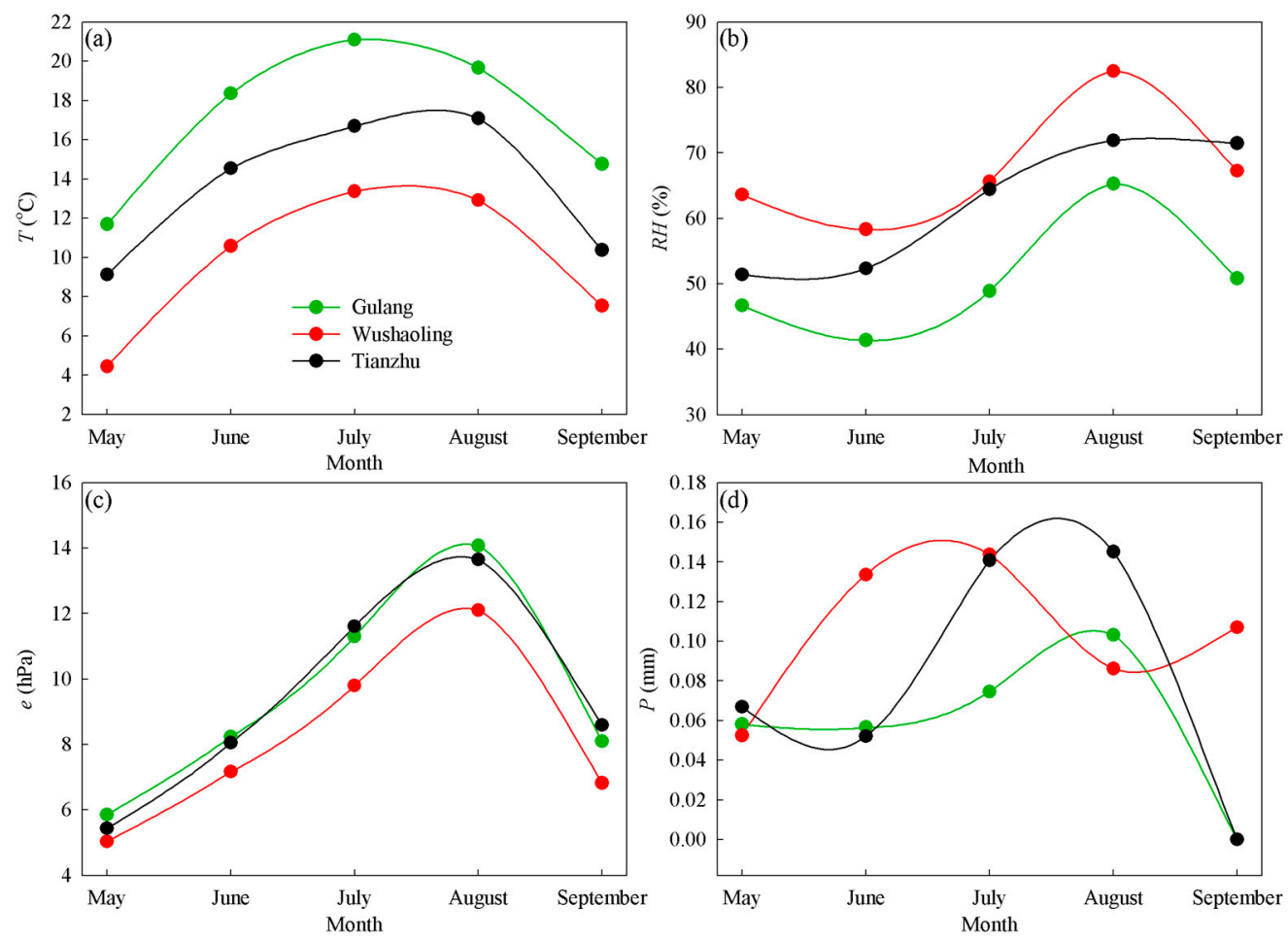

Figure 9. The monthly variations in major meteorological parameters: (a) is air temperature, (b) is relative humidity, (c) is vapor pressure, and (d) is precipitation amount.

\subsubsection{Plant Water Use Pattern}

As all plant sampling sites were located far from the rivers and groundwater, our measurements could only be used to calculate the fraction of water uptake from different soil depths, and the relationship between plant water and precipitation (if precipitation had occurred one week before sampling). Calculations were performed using the IsoSource software (Figure 10)—a stable isotope mixing model [22]. The original set of analytical solution was too vast to display, so the distribution of the default characteristic values (the mean, the minimum, the maximum, and the quartile values) are shown. Some factors, such as soil texture, vegetation coverage, and meteorological parameters, would result in different water use patterns by plants.

In different months, the water use pattern of the same plant were distinct. According to the mean value and the $50 \%$ quartile, the major water source for Caragana Fabr. at Gulang was from soil water, by month, at the $30-70 \mathrm{~cm}, 0-30 \mathrm{~cm}, 70-100 \mathrm{~cm}, 0-30 \mathrm{~cm}$, and 0-30 cm layer from May to September, respectively (Figure 10). From these results, we found that in months when no precipitation occurred before sampling, the major water source was the 0-30 cm soil layer (in June, August and September). For the months when precipitation occurred before sampling, the more often that precipitation occurred, the deeper the soil water layer that the plant used $(30-70 \mathrm{~cm}$ after three precipitation events in May, and $70-100 \mathrm{~cm}$ after four precipitation events in July). Overall, plants used direct precipitation less. 

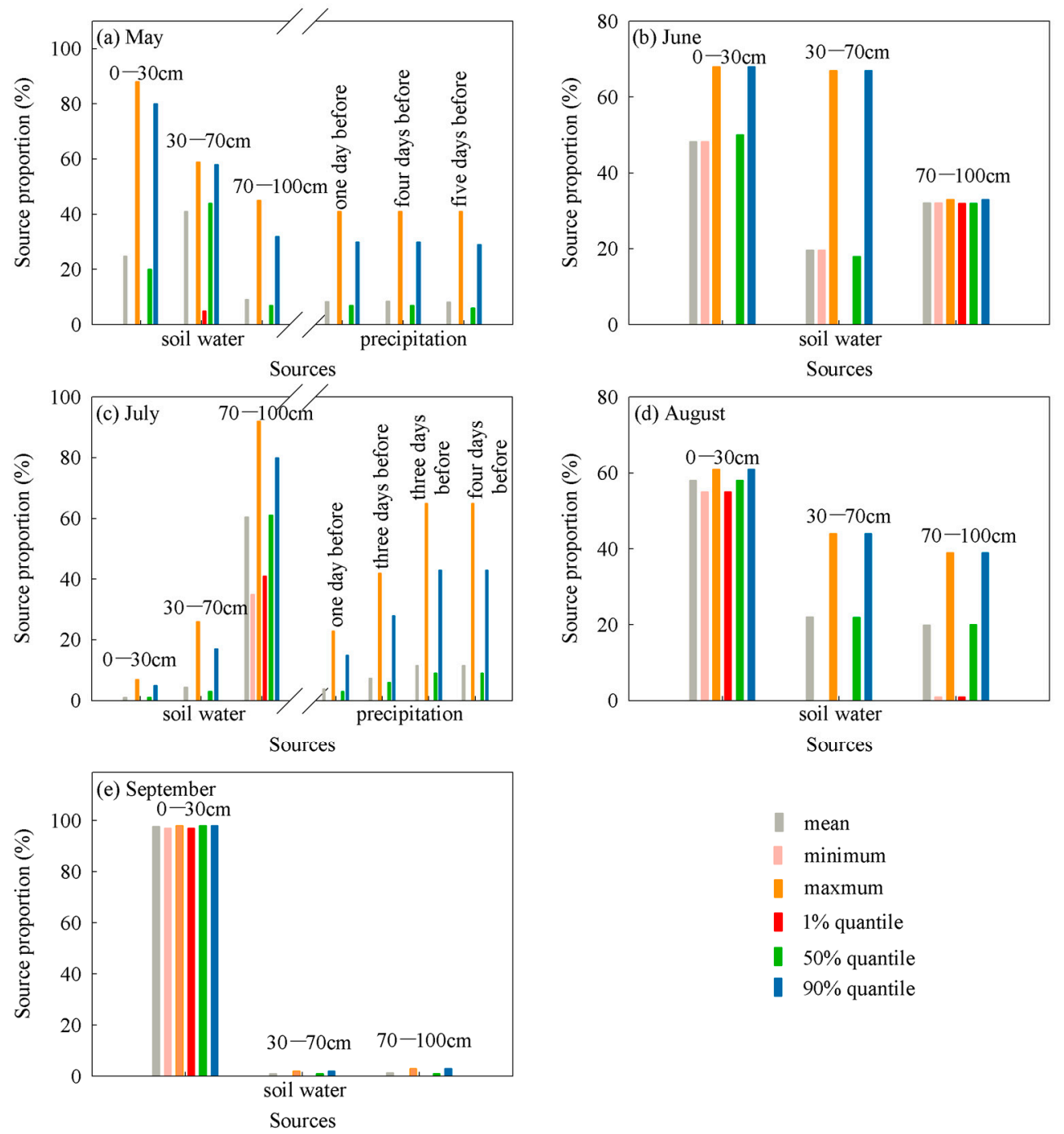

Figure 10. The fraction of plant water use from the different soil layers $(0-30 \mathrm{~cm}, 30-70 \mathrm{~cm}$, $70-100 \mathrm{~cm}$ ) and precipitation at Gulang. (a-e) represent the months of May, June, July, August, and September, respectively.

In August, when no precipitation occurred at Wushaoling (Figure 11), the major water source was also the $0-30 \mathrm{~cm}$ layer, the same as Gulang. In the remaining months, although there were several precipitation events, the water source was distinct for each month: the 0-30 cm layer in May, similar proportions from each soil layer in June, the precipitation event one day before sampling occurred in July, and the $70-100 \mathrm{~cm}$ layer in September. 

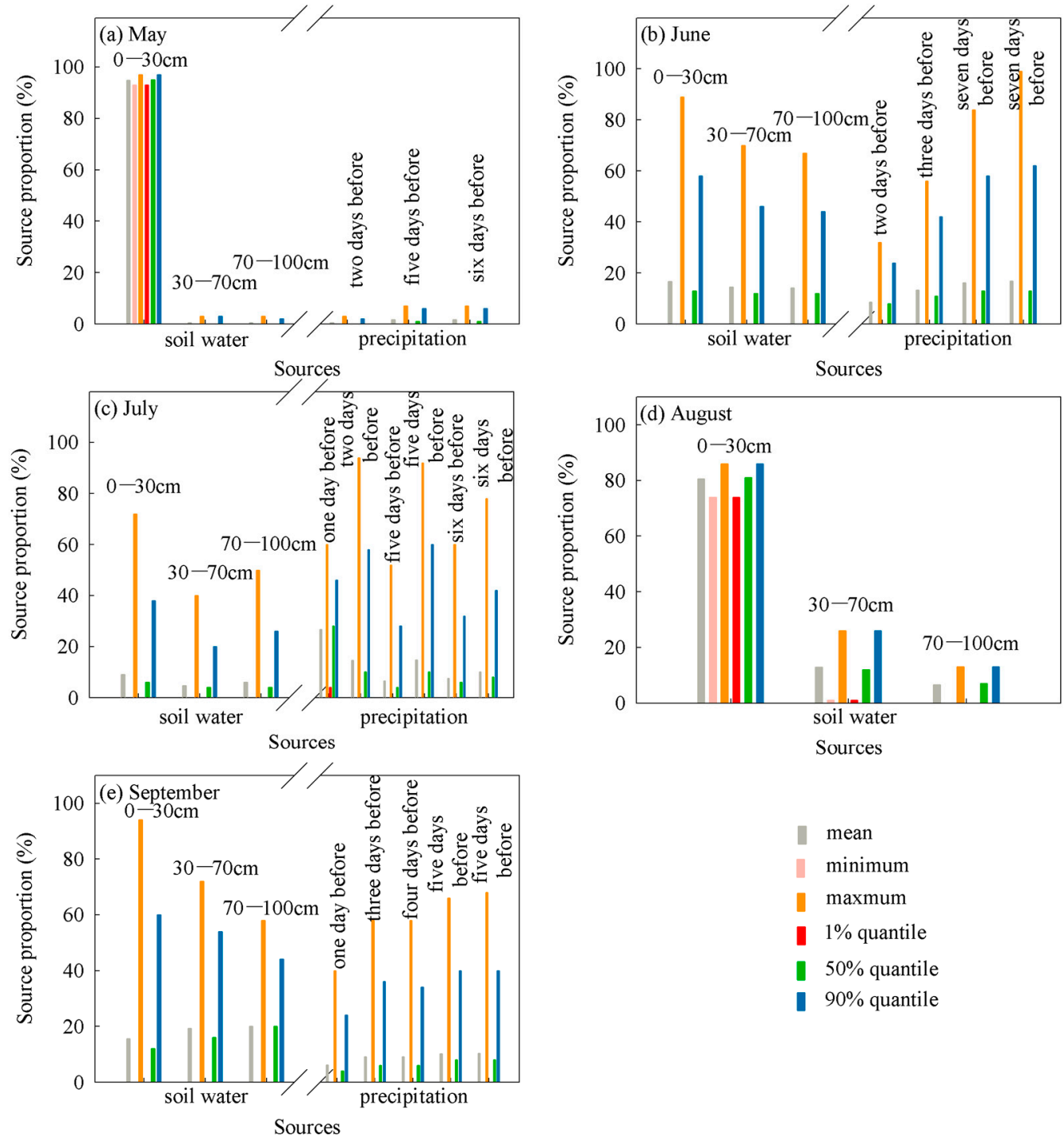

Figure 11. The fraction of plant water use from the different soil layers $(0-30 \mathrm{~cm}, 30-70 \mathrm{~cm}, 70-100 \mathrm{~cm})$ and precipitation at Wushaoling. (a-e) represent the months of May, June, July, August, and September, respectively.

For Tianzhu, in the no-precipitation month the result was the same as the above for the other two locations (Figure 12). In the other months, the water use pattern varied. The contribution of each water source to the plant water was similar in May with one precipitation event, but, in June, the proportion of water uptake from the 0-30 cm layer increased. The contribution from each water source to plant water was small in July, even with six precipitation events, but in September, with five precipitation events, the major source of plant water was the 0-30 cm layer. 

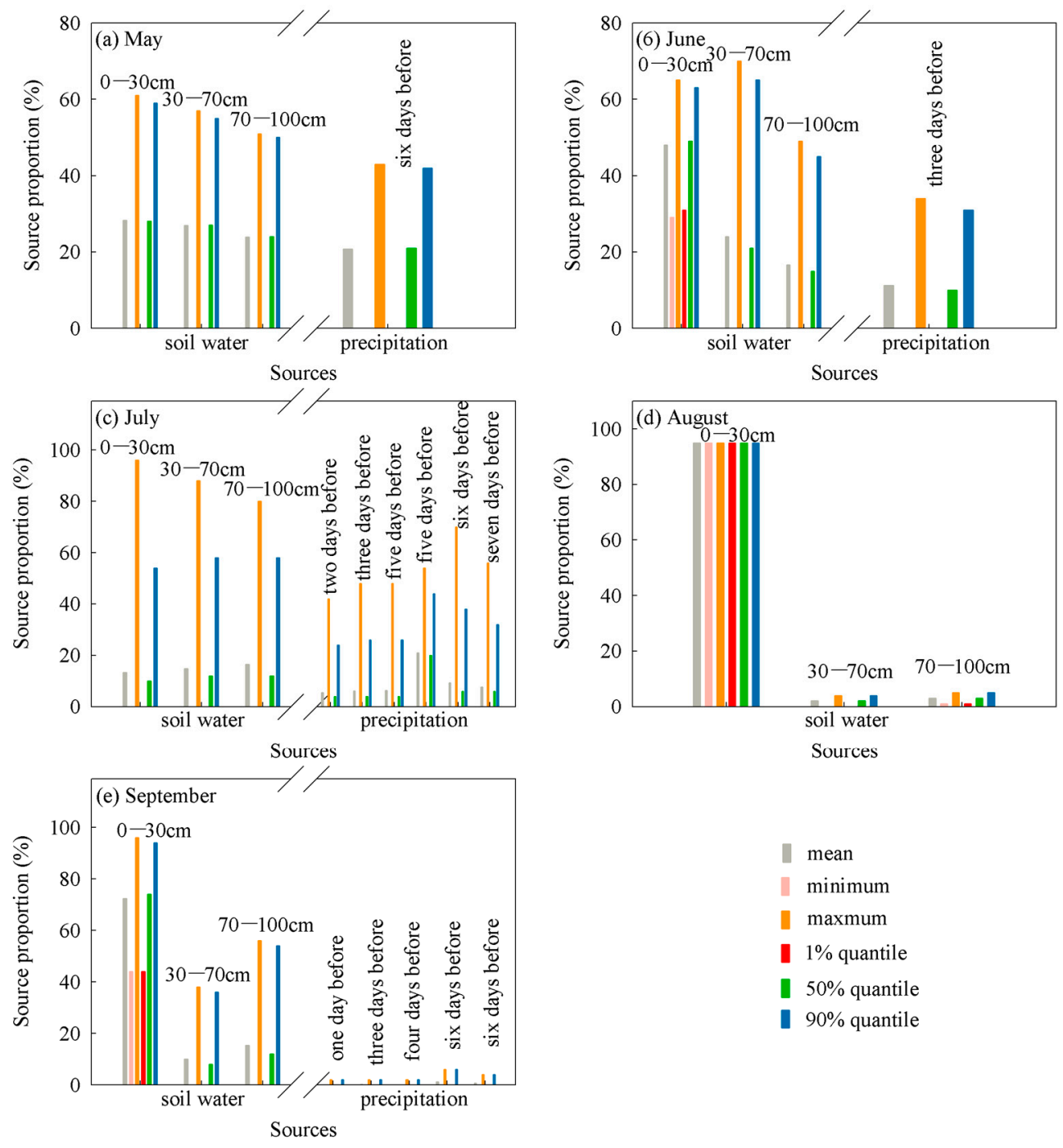

Figure 12. The fraction of plant water use from the different soil layers $(0-30 \mathrm{~cm}, 30-70 \mathrm{~cm}, 70-100 \mathrm{~cm})$ and precipitation at Tianzhu. (a-e) represents May, Jun, July, August and September, respectively.

\section{Discussion}

With regards to the water extraction system for soil and plant, Orlowski et al. [26] conducted an inter-laboratory comparison of cryogenic water extraction systems for stable isotope analysis of soil water. They showed large differences in isotopic signatures among participating laboratories, with mean differences ranging from $+18.1 \%$ o to $-108.4 \%$ o for $\delta^{2} \mathrm{H}$ and $+11.8 \%$ o to $-14.9 \%$ o for $\delta^{18} \mathrm{O}$ across all laboratories when compared to the reference water. The observed differences in isotope data were influenced by interactions between multiple factors (soil type and properties, soil water content, system setup, extraction efficiency, extraction system leaks, and the lab's internal accuracy). They suggested that laboratories might have to establish calibration functions for their specific extraction system for each natural, individual soil type.

Here, the results produced by our extraction system (LI-2100, LICA United Technology Limited, China) are evaluated, including the extraction efficiency and isotopic variation, after extraction compared to the reference water. According to its user manual, the extraction system considers temperature, vacuum, extraction time, and set build-in parameters, which users choose according to sample types.

Our test samples, including the reference water (tap water) and the soil samples with different SWC $(20 \%, 50 \%$ and $80 \%)$ filled by reference water, all had three repeats. The information on extraction 
efficiency is presented in Table 10, from which the extraction rate was an average of $98 \%$, so the water loss was very small. The change in isotope values after extraction are shown in Figure 13. The greatest difference in isotope value, before and after extraction, was $1.05 \%$ o for $\delta^{18} \mathrm{O}$ and $6.66 \%$ o for $\delta^{2} \mathrm{H}$, which were both lower than the mean differences reported by Orlowski et al. [26] when conducted by the 16 laboratories. Thus, the extraction results of our system were credible. In addition, the higher the SWC, the closer the isotope values were when compared to the original reference water after extraction.

Table 10. Information about the extraction efficiency of LI-2100.

\begin{tabular}{ccccc}
\hline Number & $\begin{array}{c}\text { Soil } \\
\text { Weight (g) }\end{array}$ & $\begin{array}{c}\text { Water Weight Filled by } \\
\text { Reference Water (g) }\end{array}$ & $\begin{array}{c}\text { Water Weight after } \\
\text { Extraction (g) }\end{array}$ & $\begin{array}{c}\text { Extraction } \\
\text { Rate (\%) }\end{array}$ \\
\hline $\mathbf{2 0 - 1}$ & 15.74 & 3.15 & 3.12 & 99 \\
$\mathbf{2 0 - 2}$ & 14.98 & 3.00 & 2.94 & 98 \\
$\mathbf{2 0 - 3}$ & 14.52 & 2.90 & 2.76 & 95 \\
$\mathbf{5 0 - 1}$ & 8.88 & 4.44 & 4.42 & 100 \\
$\mathbf{5 0 - 2}$ & 10.24 & 5.12 & 5.10 & 100 \\
$\mathbf{5 0 - 3}$ & 7.97 & 3.98 & 3.92 & 98 \\
$\mathbf{8 0 - 1}$ & 7.45 & 5.96 & 5.80 & 97 \\
$\mathbf{8 0 - 2}$ & 6.97 & 5.58 & 5.50 & 99 \\
$\mathbf{8 0 - 3}$ & 7.54 & 6.03 & 5.93 & 98 \\
\hline
\end{tabular}
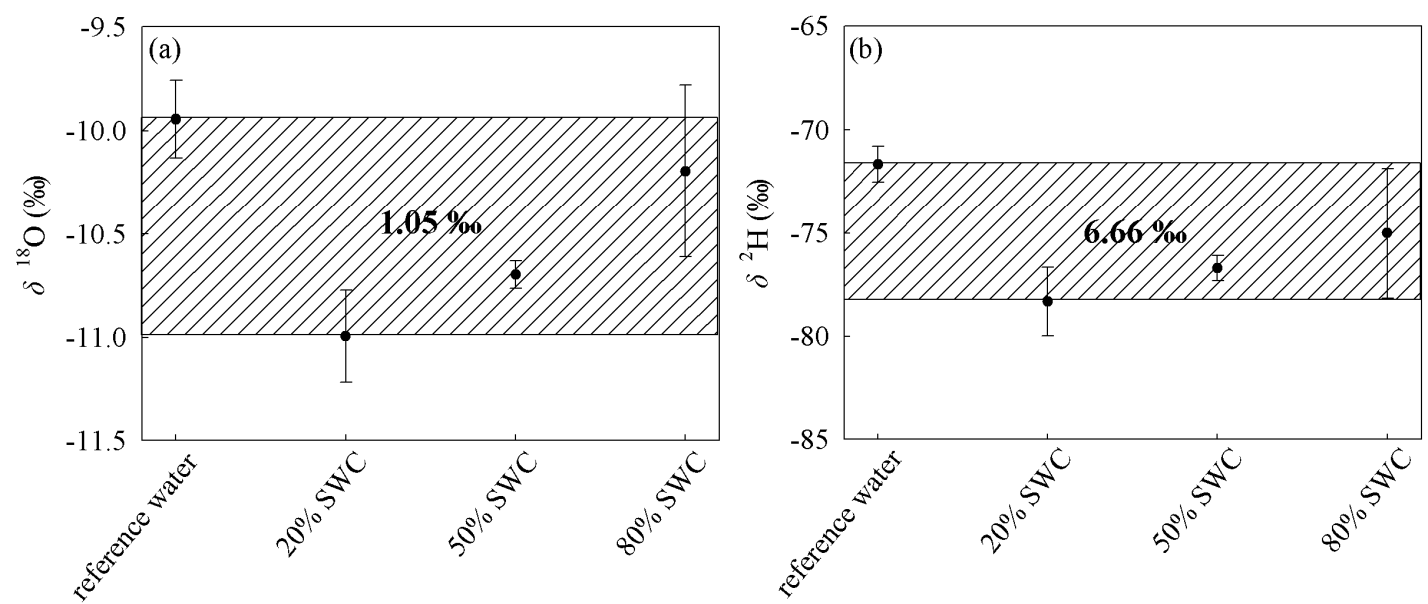

Figure 13. The isotopic differences for the soil samples with different SWC and the reference water. $(\mathbf{a}, \mathbf{b})$ are for $\delta^{18} \mathrm{O}$ and $\delta^{2} \mathrm{H}$, respectively.

It should be noted that the soil water and the plant stem water measured by the Liquid Water Isotope Analyzer need to be detected for water contamination. The LWIA Spectral Contamination Identifier (LWIA-SCI) software is a simple tool, provided by Los Gatos Research (LGR), to identify features that are consistent with water contamination in the spectra recorded by LGR's liquid water isotope analyzer. The LWIA-SCI analyzes the data files and the recorded spectra from the LWIA to produce a metric that indicates the likelihood of contamination from either narrow-band or broad-band absorbers. This metric is compared to the known clean samples (general standards) in the data set and produces a good or bad flag to indicate the reliability of the associated isotopic ratio measurements.

Finally, we should note that, since only a one-year dataset was used and the number of sampling sites was limited, longer datasets and more sampling sites are required to confirm these findings. Also, the use of water by plants from different soil depths was studied, without considering other water sources. In future sampling campaigns, additional sampling points near rivers and wells should be considered, in order to take into account all of the potential water sources and the proportion of their contribution to plant water. In order to better understand the changes in the isotopic signatures of different water bodies before and after precipitation, especially the change in water use strategy by 
plants, several typical precipitation events should be selected and samples collected before and after the precipitation event.

\section{Conclusions}

In this study we selected three sampling sites, specifically Gulang, Wushaoling and Tianzhu, located in the northeastern Tibetan Plateau. Event-based precipitation samples were collected for a complete year. Monthly samples of plant water, soil water, river water, and groundwater were collected for a complete growing season. The isotopic characteristics of the various water bodies, the recharge relationships among them, and the fraction of water uptake from different soil layers were studied.

The "temperature effect" was apparent at the three sites, suggesting an evaporation enrichment. Using the six regressions (OLSR, MA, RMA, PWLSR, PWMA, PWRMA), the slope differences among the various methods were tested, and were the smallest for Wushaoling, followed by Tianzhu, with the largest difference in Gulang. The $\delta^{18} \mathrm{O}$ of soil water varied significantly in the topsoil layers, while they tended to be similar in deep soil. The isotopes became increasingly depleted along the vertical soil profile, from top to bottom. The changes in monthly $\delta^{18} \mathrm{O}$ and $\delta^{2} \mathrm{H}$ were minor, but soil temperature visibly changed, which showed that temperature was not the sole factor that impacted soil water isotopes. The soil water isotopes at the different sites had different responses to precipitation, and they had variable soil layer boundaries, where Wushaoling's soil boundary layers were located at 20 and 60 $\mathrm{cm}$ below the surface, while for Tianzhu this was located at $40 \mathrm{~cm}$. The consistent variation in $\delta^{18} \mathrm{O}$ and $\delta^{2} \mathrm{H}$ for river water and groundwater indicated a similar source water. The similarities between these two water bodies showed a water exchange process. The relationship among precipitation, river water, and groundwater was distinct at all three sites. The hydraulic connection of river water and groundwater was stronger at Wushaoling and Tianzhu than at Gulang. Using the isotope data from the xylem of the same plant genus (Caragana Fabr.) sampled at three sites and applying the IsoSource model, it was found that the water use pattern of plants varied with both month and site location, but was the same between sites in no-precipitation months, i.e., plant water relied on soil water at $0-30 \mathrm{~cm}$.

Author Contributions: Conceptualization, M.Z.; methodology, X.Q.; investigation, R.G.; resources, R.C. and H.M.; writing—original draft preparation, X.Q.; writing—review and editing, S.W. and A.A.

Funding: This research was funded by National Natural Science Foundation of China, grant number 41461003; 41771035 and Scientific Research Program of Higher Education Institutions of Gansu Province, grant number 2018C-02.

Acknowledgments: The authors greatly thank all the meteorological stations for their warm help in field sampling. We also thank the colleagues in the Northwest Normal University for in laboratory analyzing and field work, especially thank Xiuxiu Yu, Sue Zhou and Yaning Zhang.

Conflicts of Interest: The authors declare no conflict of interest.

\section{References}

1. Tan, H.; Wen, X.; Rao, W.; Bradd, J.; Huang, J. Temporal variation of stable isotopes in a precipitation-groundwater system: Implications for determining the mechanism of groundwater recharge in high mountain-hills of the Loess Plateau, China. Hydrol. Process. 2016, 30, 1491-1505. [CrossRef]

2. He, S.; Richards, K. Stable isotopes in monsoon precipitation and water vapour in Nagqu, Tibet, and their implications for monsoon moisture. J. Hydrol. 2016, 540, 615-622. [CrossRef]

3. Hu, H.; Dominguez, F. Evaluation of oceanic and terrestrial sources of moisture for the north American monsoon using numerical models and precipitation stable isotopes. J. Hydrometeorol. 2015, 16, 19-35. [CrossRef]

4. Evaristo, J.; McDonnell, J.J.; Scholl, M.A.; Bruijnzeel, L.A.; Chun, K.P. Insights into plant water uptake from xylem-water isotope measurements in two tropical catchments with contrasting moisture conditions. Hydrol. Process. 2016, 30, 3210-3227. [CrossRef]

5. Yang, B.; Wen, X.; Sun, X. Irrigation depth far exceeds water uptake depth in an oasis cropland in the middle reaches of Heihe River Basin. Sci. Rep. 2015, 5, 15206. [CrossRef] 
6. Yang, B.; Wen, X.; Sun, X. Seasonal variations in depth of water uptake for a subtropical coniferous plantation subjected to drought in an East Asian monsoon region. Agric. For. Meteorol. 2015, 201, 218-228. [CrossRef]

7. Wan, H.; Liu, W. An isotope study $\left({ }^{18} \mathrm{O}\right.$ and D) of water movements on the Loess Plateau of China in arid and semiarid climates. Ecol. Eng. 2016, 93, 226-233. [CrossRef]

8. Lee, K.S.; Kim, J.M.; Lee, D.R.; Kim, Y.; Lee, D. Analysis of water movement through an unsaturated soil zone in Jeju Island, Korea using stable oxygen and hydrogen isotopes. J. Hydrol. 2007, 345, 199-211. [CrossRef]

9. Marchina, C.; Bianchini, G.; Natali, C.; Pennisi, M.; Colombani, N.; Tassinari, R.; Knoeller, K. The Po river water from the Alps to the Adriatic Sea (Italy): New insights from geochemical and isotopic $\left(\delta^{18} \mathrm{O}-\delta \mathrm{D}\right)$ data. Environ. Sci. Pollut. Res. 2015, 25, 5184-5203. [CrossRef] [PubMed]

10. Chiogna, G.; Santoni, E.; Camin, F.; Tonon, A.; Majone, B.; Trenti, A.; Bellin, A. Stable isotope characterization of the Vermigliana catchment. J. Hydrol. 2014, 509, 295-305. [CrossRef]

11. Liu, J.; Chen, Z.; Zhang, Y.; Liu, F. Stable isotope evidences on sources and mechanisms of groundwater recharge in Hohhot basin, China. Environ. Earth Sci. 2016, 75, 410-420. [CrossRef]

12. Jasechko, S.; Birks, S.J.; Gleeson, T.; Wada, Y.; Fawcett, P.J.; Sharp, Z.D.; McDonnell, J.J.; Welker, J.M. The pronounced seasonality of global groundwater recharge. Water Resour. Res. 2014, 50, 8845-8867. [CrossRef]

13. Li, Z.; Gui, J.; Wang, X.; Feng, Q.; Zhao, T.; Ouyang, C.; Guo, X.; Zhang, B.; Shi, Y. Water resources in inland regions of central Asia: Evidence from stable isotope tracing. J. Hydrol. 2019, 70, 1-16. [CrossRef]

14. Li, Z.; Feng, Q.; Yong, S.; Wang, Q.J.; Jiao, Y.; Li, Y.; Li, J.; Guo, X. Stable isotope composition of precipitation in the south and north slopes of Wushaoling Mountain, northwestern China. Atmos. Res. 2016, 182, 87-101. [CrossRef]

15. Ma, J.; Zhang, P.; Zhu, G.; Wang, Y.; Edmunds, W.M.; Ding, Z.; He, J. The composition and distribution of chemicals and isotopes in precipitation in the Shiyang River system, northwestern China. J. Hydrol. 2012, 436-437, 92-101. [CrossRef]

16. Zhao, L.; Yin, L.; Xiao, H.; Cheng, G.; Zhou, M.; Yang, Y.; Li, C.; Zhou, J. Isotopic evidence for the moisture origin and composition of surface runoff in the headwaters of the Heihe River basin. Chin. Sci. Bull. 2011, 56, 406-416. [CrossRef]

17. Wu, J.; Ding, Y.; Ye, B.; Yang, Q.; Zhang, X.; Wang, J. Spatio-temporal variation of stable isotopes in precipitation in the Heihe River Basin, Northwestern China. Environ. Earth Sci. 2010, 61, 1123-1134. [CrossRef]

18. Wang, Y.; Wang, J.; Qi, Y.; Yan, C. Dataset of Desert Distribution in China (1:100,000). Cold and Arid Regions Science Data Center at Lanzhou (CARD), 2005. Available online: http://doi.org/10.3972/westdc.006.2013.db (accessed on 30 December 2018).

19. IAEA. Statistical Treatment of Data on Environmental Isotopes in Precipitation; Technical Report Series; IAEA: Vienna, Austria, 1992; Volume 331, p. 781.

20. Crawford, J.; Hughes, C.E.; Lykoudis, S. Alternative least squares methods for determining the meteoric water line, demonstrated using GNIP data. J. Hydrol. 2014, 519, 2331-2340. [CrossRef]

21. Hughes, C.E.; Crawford, J. Anew precipitation weighted method for determining the meteoric water line for hydrological applications demonstrated using Australian and global GNIP data. J. Hydrol. 2012, 464-465, 344-351. [CrossRef]

22. Phillips, D.L.; Gregg, J.W. Source partitioning using stable isotopes: Coping with too many sources. Oecologia 2003, 136, 261-269. [CrossRef]

23. Dansgaard, W. Stable isotopes in precipitation. Tellus 1964, 16, 436-468. [CrossRef]

24. Craig, H. Isotopic variations in meteoric waters. Science 1961, 133, 1702-1703. [CrossRef]

25. Gat, J.R. Oxygen and hydrogen isotopes in the hydrologic cycle. Annu. Rev. Earth Planet. Sci. 1996, 24, 225-262. [CrossRef]

26. Orlowski, N.; Breuer, L.; Angeli, N.; Boeckx, P.; Brumbt, C.; Cook, C.S.; Dubbert, M.; Dyckmans, J.; Gallagher, B.; McDonnell, J.J.; et al. Inter-laboratory comparison of cryogenic water extraction systems for stable isotope analysis of soil water. Hydrol. Earth Syst. Sci. 2018, 22, 3619-3637. [CrossRef]

(C) 2019 by the authors. Licensee MDPI, Basel, Switzerland. This article is an open access article distributed under the terms and conditions of the Creative Commons Attribution (CC BY) license (http://creativecommons.org/licenses/by/4.0/). 